\title{
First report on detection of Babesia spp. in confiscated Sunda pangolins (Manis javanica) in Thailand
}

\author{
Rungrueang Yodsheewan ${ }^{1}(\mathbb{D})$, Manakorn Sukmak 2,3 , Bencharong Sangkharak ${ }^{4} \mathbb{D}$, Nongnid Kaolim ${ }^{3}$ (D), Raveewan Ploypan ${ }^{1}$ (D) \\ and Wallaya Phongphaew ${ }^{1}$ (D)
}
1. Department of Pathology, Faculty of Veterinary Medicine, Kasetsart University, Bangkhen Campus, Bangkok, Thailand; 2. Department of Farm Resources and Production Medicine, Faculty of Veterinary Medicine, Kasetsart University, Kamphaeng Saen Campus, Nakhon Pathom, Thailand; 3. Kamphangsaen Veterinary Diagnostic Center, Faculty of Veterinary Medicine, Kasetsart University, Kamphaeng Saen, Nakhon Pathom, Thailand; 4. Department of National Parks, Wildlife and Plant Conservation, Bangkok, Thailand.
Corresponding author: Wallaya Phongphaew, e-mail: fvetwyp@ku.ac.th
Co-authors: RY: fvetrry@ku.ac.th, MS: fvetmksu@ku.ac.th, BS: vacuummm@hotmail.com, NK: nongnid_2522@hotmail.com, RP: ploypan0642@gmail.com
Received: 21-04-2021, Accepted: 02-08-2021, Published online: 13-09-2021

doi: www.doi.org/10.14202/vetworld.2021.2380-2385 How to cite this article: Yodsheewan $R$, Sukmak $M$, Sangkharak B, Kaolim N, Ploypan R, Phongphaew W (2021) First report on detection of Babesia spp. in confiscated Sunda pangolins (Manis javanica) in Thailand, Veterinary World, 14(9): 2380-2385.

\begin{abstract}
Background and Aim: The Sunda pangolin (Manis javanica) is on the International Union for Conservation of Nature Red List of Threatened Species (critically endangered) due to high levels of illegal trafficking for its products. Thailand is one of the habitats of this species, and it has become the main hub for its illegal trafficking. Rehabilitating these captive pangolins and reintroducing them back to the wild are challenging due to the limited knowledge on their diet, management, and diseases. Hemoparasites, including Babesia spp., can cause important protozoal infections in both domestic and wild animals, resulting in the failure of rehabilitation and conservation programs. However, Babesia spp. has not been reported in pangolins. The aim of the study was to determine the prevalence of Babesia spp. in the Sunda pangolin of Thailand.
\end{abstract}

Materials and Methods: A total of 128 confiscated Sunda pangolins from across different regions in Thailand were investigated. These pangolins had been admitted to a regional Wildlife Quarantine Center for rehabilitation before release in the forest. Routine physical examinations were conducted on the animals. We collected blood samples from each pangolin for hematological analysis and to detect Babesia spp. using polymerase chain reaction (PCR) targeting the partial $18 s$ rRNA gene.

Results: Babesia-specific PCR detected 53 animals (41.4\%) that were positive for Babesia spp. Blood smears were obtained from the positive samples and investigated under a light microscope to observe for trophozoites of Babesia spp. Examination of 40 PCR-positive and -negative samples found no significant differences between the hematological parameters of Babesia-positive and Babesia-negative samples. Eight PCR-positive samples were randomly selected and their DNA was sequenced. Seven and one of sequences match uncharacterized Babesia spp. with $100 \%$ and $99.2 \%$ similarity, respectively. Phylogenetic analysis demonstrated that our samples form a unique monophyletic clade along with other Babesia spp. detected in the wild. This clade is clearly separated from other Babesia spp. from small carnivores, ruminants, and rats.

Conclusion: Our results provide evidence of infection of Sunda pangolins in Thailand by Babesia spp. These pangolins originated from different regions and had not lived together before blood collection. Thus, we suggest that the uncharacterized Babesia spp. found in this study constitute a new group of pangolin-specific Babesia spp. The prevalence of the uncharacterized Babesia spp. was not correlated to pangolin health. Further studies are required to characterize the genomes and phenotypes, including the morphology and pathogenicity of these protozoa. Such information will be helpful for the conservation and health management of the Sunda pangolin.

Keywords: Babesia spp., Manis javanica, sunda pangolin, Thailand.

\section{Introduction}

The Sunda or Malayan pangolin (Manis javan$i c a)$ is classified as critically endangered on the International Union for Conservation of Nature Red List of Threatened Species [1]. It is widely distributed in several countries across Southeast Asia, including

Copyright: Yodsheewan, et al. Open Access. This article is distributed under the terms of the Creative Commons Attribution 4.0 International License (http://creativecommons.org/licenses/ by/4.0/), which permits unrestricted use, distribution, and reproduction in any medium, provided you give appropriate credit to the original author(s) and the source, provide a link to the Creative Commons license, and indicate if changes were made. The Creative Commons Public Domain Dedication waiver (http:// creativecommons.org/publicdomain/zero/1.0/) applies to the data made available in this article, unless otherwise stated.
Thailand [2]. However, populations of the Sunda pangolin have been gradually decreasing because of increasing threats; therefore, this species has received considerable attention regarding its conservation. Attempts to reproduce pangolins in captivity have usually been unsuccessful because of limited knowledge of their ecology and biology. Among captive pangolins, parasite infestation is one of the most common causes of morbidity and mortality [3], and among such parasites, Babesia spp. is known to infect humans and several kinds of animals throughout the world [4]. Babesia spp. belongs to the order Piroplasmida within phylum Apicomplexa, and it is closely related to Theileria spp. and Cytauxzoon spp. [5,6]. These three genera 
are referred to as piroplasms due to their pear-shaped (pyriform) intraerythrocytic stages. Babesia spp. are transmitted by hard ticks and cause morbidity and mortality in many species of mammals, both domestic and wild [4,5,7-12]. Babesiosis is a disease that can range from being asymptomatic to lethal [4,13-17].

The previous studies have reported the detection of some hemoparasites such as Anaplasma spp., Rickettsia conorii, Ehrlichia spp., and Cytauxzoon spp. in pangolins [18,19]. Although Babesia spp. has not been reported in pangolins, it is possible for pangolins to carry Babesia spp. to the detriment of their health. Moreover, studying babesiosis in pangolins may provide important information for pangolin conservation.

This study aimed to investigate the prevalence of Babesia spp. in Sunda pangolins and compared the blood parameters of infected and non-infected pangolins to clarify the association between babesiosis and pangolin health.

\section{Material and Methods \\ Ethical approval}

This animal use protocol has been submitted and reviewed by the Kasetsart University Institutional Animal Care and Use Committee and found to be in accordance to the guidelines of animal care and use under the Ethical Review Board of the Office of National Research Council of Thailand (NRCT) for the conduction of the scientific research. The committee approved and permitted the animal care and use to be conducted as stated in the research study in this animal use protocol (license number ACKU62-VET-053).

\section{Study period and location}

The study was conducted from February to December 2019. The samples were collected from three provinces from central and southern Thailand, including Sukhothai, Nakorn Nayok, and Songkhla. The samples were processed at Laboratory of Department of Pathology, Faculty of Veterinary Medicine, Kamphangsaen campus.

\section{Sample collection}

Blood samples were collected from 128 confiscated Sunda pangolins confined in three local Wildlife Quarantine Centers in Sukhothai (A; $n=40)$, Nakorn Nayok $(B ; n=38)$, and Songkhla $(C ; n=50)$ provinces, Thailand. Whole blood samples were collected aseptically through the tail vein using a 22-gauge needle and a $5 \mathrm{ml}$ syringe. Each $5 \mathrm{ml}$ sample of whole blood was mixed with ethylenediaminetetraacetic acid (EDTA) in a Vacutainer blood collection tube (BD, NJ, USA). Blood samples were kept at $4^{\circ} \mathrm{C}$ before polymerase chain reaction (PCR) and hematological analysis at Kasetsart University, Kamphaeng Saen Campus, Nakorn Pathom, Thailand.

\section{Molecular analysis}

DNA was extracted using a TIANamp Blood DNA kit (TIANGEN ${ }^{\circledR}$, China) following the manufacturer's protocol. PCR to detect Babesia spp. was performed using Phusion High-fidelity DNA Polymerase (Thermo Scientific, MA, USA) with previously reported Babesia spp.-specific primers targeting the $18 S r R N A$ gene: BAB $1 \mathrm{w}$ (5'-GAA CCT GGT TGA TCC TGC CAG T-3') and BAB2w (5'-GAT CCT TCT GCA GGT TCA CCT A-3') [20]. The PCR was performed in a Peltier thermal cycler (model PTC-200; BioRad, California, USA) programmed to run at $98^{\circ} \mathrm{C}$ for $30 \mathrm{~s}$, followed by 40 cycles of $98^{\circ} \mathrm{C}$ for $30 \mathrm{~s}, 58^{\circ} \mathrm{C}$ for $30 \mathrm{~s}$, and $72^{\circ} \mathrm{C}$ for $90 \mathrm{~s}$, ending with a final extension of $72^{\circ} \mathrm{C}$ for $5 \min [20]$. The PCR products were visualized by $1.5 \%$ agarose with iMyRun.N (Cosmo Bio, Japan) for electrophoresis using GelStar ${ }^{\mathrm{TM}}$ Nucleic Acid gel stain (Lonza, Switzerland).

\section{Hematological analyses}

The complete blood counts of 40 representative samples (from 10 males and 10 females that tested PCR negative and positive, respectively) were measured using a Sysmex xt-2000i automated hematology analyzer (Sysmex, Japan). Serum proteins were measured using a refractometer (Brouwland, Belgium). The EDTA-treated blood from the PCR-positive samples was smeared onto glass slides, fixed in absolute methanol, and stained with modified Wright's stain to observe for blood parasites under a light microscope.

\section{Sequencing and phylogenetic analyses}

We randomly selected samples from eight Babesia spp.-positive pangolins, ensuring that each different region was represented in these samples. The purified PCR products from these samples were sequenced by the First Base Laboratory, Shah Alam, Malaysia, using the detection primer using BigDye ${ }^{\circledR}$ (Thermo Fisher Scientific) Terminator v3.1 cycle sequencing kit (Applied Biosystems, CA, USA) and an ABI PRISM3130 Automated DNA Sequencer (Ibis Biosciences, CA, USA) The different Babesia spp. sequences were aligned using ClustalW set to default parameters using BioEdit software (Ibis Biosciences). Phylogenetic analysis was conducted using MEGA 6 software (https://www.megasoftware.net/) using a maximum-likelihood method based on the Tamura 3-parameter model with $\mathrm{G}+\mathrm{I}$ (1000 replicates of bootstrap analysis were performed).

\section{Results}

A total of 128 blood samples were obtained from Sunda pangolins that had been confiscated from illegal traffickers and housed at three regional rehabilitation and conservation centers. PCR on blood samples using Babesia spp.-specific $18 S$ rRNA gene primers indicated that $41.4 \%(53 / 128)$ of the samples were positive for the presence of Babesia spp. Pangolins from regions $\mathrm{A}, \mathrm{B}$, and $\mathrm{C}$ were represented in the positive samples. The highest prevalence of Babesia spp. was in region $\mathrm{A}$, at $65 \%(26 / 40)$, while prevalence values in regions $\mathrm{B}$ and $\mathrm{C}$ were $21 \%(8 / 38)$ and $38 \%$ (19/50), respectively (Table-1). The PCR products 
from eight randomly selected positive samples $(8 / 53)$ were sequenced and are hereafter referred to as follows: A63, A68, A70, BMDN16, BMDN37, CASM2, CASM15, and CASM21; their GenBank accession numbers, respectively, are as follows: MZ173490, MZ173491, MZ173492, MZ173493, MZ173494, MZ173495, MZ173496, and MZ173497. None of the eight sequences from the Babesia spp.-positive pangolins fully matched any of the sequences in GenBank. Babesia spp. sequences generated in this study were most similar (95.43\% identity) to Babesia spp. that

Table-1: Number of positive samples for each sampling region

\begin{tabular}{lccc}
\hline Region & $\begin{array}{c}\text { Number } \\
\text { of } \\
\text { samples }\end{array}$ & $\begin{array}{c}\text { Number } \\
\text { of positive } \\
\text { samples }\end{array}$ & $\begin{array}{c}\text { Percentage } \\
\text { of positive } \\
\text { samples }\end{array}$ \\
\hline A & 40 & 26 & $65 \%(26 / 40)$ \\
B & 38 & 21 & $55.3 \%(21 / 38)$ \\
C & 50 & 19 & $38 \%(19 / 50)$ \\
\hline
\end{tabular}

have been reported in the mane wolf (accession number: KR107880) as well as other Babesia spp. isolated from other wild animals. Multiple alignments of eight 782 bp long sequences demonstrate that the Babesia spp. detected in this study belong to two different genotypes The eight Babesia spp. sequences were $99.20 \%-100 \%$ identical. We did not detect any coinfection by these two different genotypes in this study.

A phylogenetic tree (Figure-1) was constructed based on partial $18 s$ rRNA sequences to verify the evolutionary relationships between pangolin-associated and other Babesia spp. [21]. Figure-1 shows that pangolin-associated Babesia spp. are segregated on a distinct branch that is monophyletically clustered with Babesia spp. from other wildlife (such as wolf, deer, and raccoon). This branch is clearly separated from Babesia spp. reported in domestic animals, small carnivores (Babesia gibsoni and Brucella canis), ruminants (Babesia major, Babesia bigemina, and Babesia

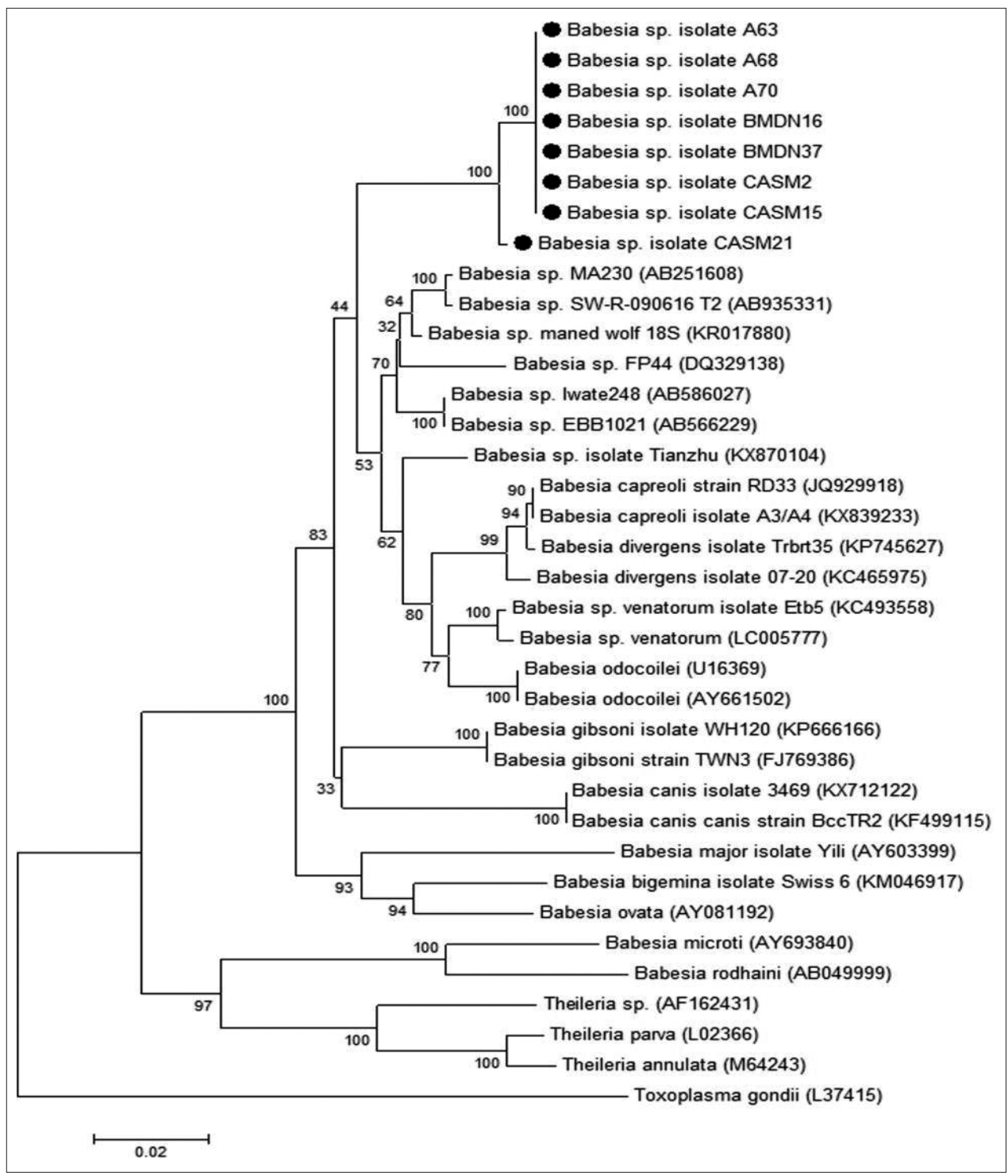

Figure-1: Phylogenetic analysis among Babesia spp. based on partial 18s rRNA gene (782 bp). Number in brackets is GenBank accession numbers. The representative sequences of pangolin-associated Babesia spp. obtained in this study are marked with black circle. The phylogenetic tree was constructed using MEGA 6 [21] under a maximum-likelihood method based on Tamura 3-parameter model with G+I (1000 replicates of bootstrap analysis were performed). 
ovatus), and rats (Babesia microti and Babesia rodhaini). The phylogenetic tree includes Theileria spp. sequences to provide a better understanding of the evolutionary history of this group and Toxoplasma gondii was used as an outgroup.

Because of the hemotropic properties of Babesia spp., we compared the hematological parameters of Babesia spp.-positive and -negative samples to investigate the association between the presence of Babesia spp. and the health status of Sunda pangolins. Blood samples that were positive $(n=20)$ and negative $(n=20)$ for Babesia spp. were analyzed for complete blood count and serum protein, and the results are shown in Table-2 [22]. The hematological parameters between Babesia spp.-positive and -negative samples did not differ significantly $(\mathrm{p} \leq 0.01)$ (Table-2). In addition, the hematological values of Babesia spp.-positive pangolins were within their normal ranges (Table-2).

Analysis of blood smears with modified Wright's stain demonstrated that Babesia spp. are intraerythrocytic, pyriform, and round (Figure-2a and b). However, the number of Babesia spp. in blood smears tended to be low.

\section{Discussion}

The results indicate that $41.4 \%$ of pangolins confiscated from illegal traffickers are infected with uncharacterized Babesia spp. Interestingly, these infected pangolins had the same type of Babesia spp., and they originated from different regions in Thailand and did not live together before blood collection. This implies that a pangolin-specific species of Babesia are widely distributed throughout Thailand. The results of the sequencing and phylogenetic analysis indicate that the pangolin-associated Babesia spp. are novel species that are genetically most similar to Babesia spp. reported in other wildlife. The phylogenetic tree indicates that pangolin-associated Babesia spp. share a common ancestor with other Babesia spp. detected in wildlife and are distinct from Babesia spp. that have been reported in domestic animals and rats. However, the pathogenic potential of the pangolin-associated Babesia spp. is still unknown.

The hematological analyses indicate that the hematological profiles of Babesia spp.-infected and non-infected pangolins are not significantly different. In addition, microscopy revealed only small numbers

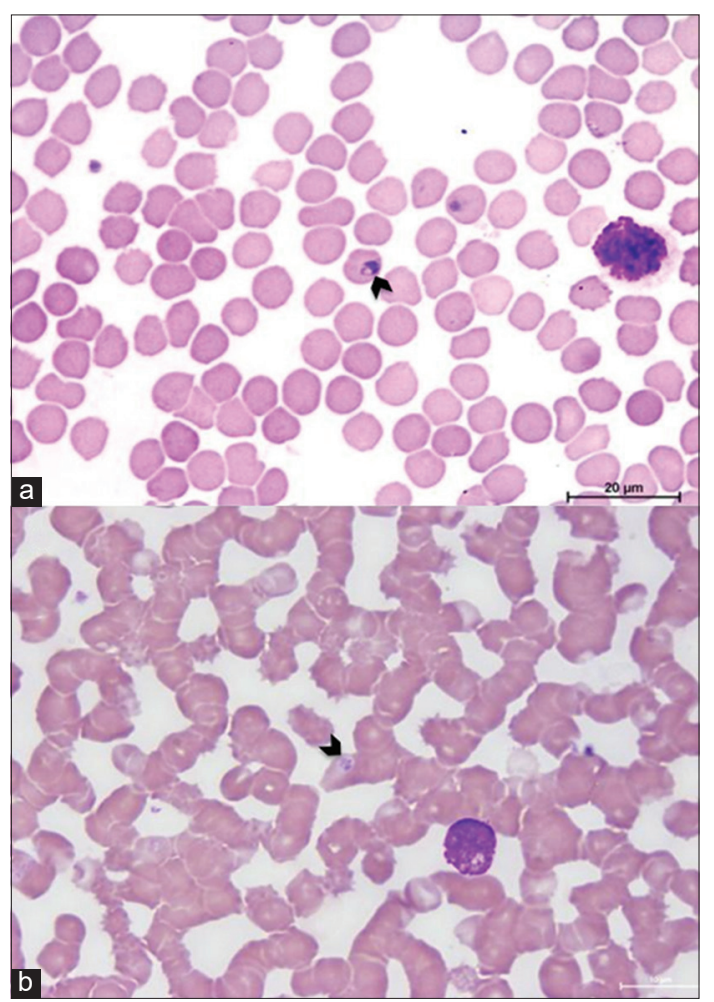

Figure-2: (a) Large pyriform shape intraerythrocytic trophozoite of pangolin-associated Babesia spp. (arrow head), 100x. (b) Small round shape of intraerythrocytic trophozoite of pangolin-associated Babesia spp. (arrow head), $100 \times$.

Table-2: Comparison of hematological values between Babesia-PCR-positive and -negative Sunda pangolins, $\mathrm{n}=20$ ( female $=10$, male $=10)$. No significant $(p \leq 0.01)$ differences of hematological parameters were identified between PCRpositive and PCR-negative samples.

\begin{tabular}{|c|c|c|c|c|}
\hline \multirow{2}{*}{$\begin{array}{l}\text { Hematological } \\
\text { parameter }\end{array}$} & \multicolumn{2}{|c|}{ Babesia-PCR status } & \multirow[t]{2}{*}{$p$-value $(\leq 0.01)$} & \multirow[t]{2}{*}{ Reference range [22] } \\
\hline & $\begin{array}{c}\text { Babesia-positive } \\
\text { Mean } \pm \text { SD } \\
(n=20)\end{array}$ & $\begin{array}{c}\text { Babesia-negative } \\
\text { Mean } \pm \text { SD } \\
(\mathbf{n}=\mathbf{2 0})\end{array}$ & & \\
\hline $\mathrm{RBC} \times 10^{12} / /$ & $6.31 \pm 0.52$ & $6.30 \pm 0.51$ & 0.952 & $1.92-9.65$ \\
\hline HCT (\%) & $38.21 \pm 2.85$ & $39.33 \pm 3.14$ & 0.457 & $25.00-55.00$ \\
\hline $\operatorname{MCV}(f /)$ & $60.73 \pm 2.05$ & $62.57 \pm 1.988$ & 0.073 & $56.00-75.00$ \\
\hline $\mathrm{MCHC}(\mathrm{g} / \mathrm{I})$ & $350.9 \pm 7.8$ & $350.2 \pm 12.4$ & 0.907 & $289.00-426.00$ \\
\hline $\mathrm{MCH}(\mathrm{pg})$ & $21.21 \pm 0.82$ & $21.89 \pm 0.69$ & 0.077 & $17.30-29.50$ \\
\hline Plasma protein $(\mathrm{g} / \mathrm{l})$ & $7.65 \pm 0.71$ & $7.86 \pm 0.84$ & 0.589 & $50.00-93.00$ \\
\hline WBC Count $\left(\times 10^{9} / I\right)$ & $10.06 \pm 2.18$ & $7.49 \pm 2.17$ & 0.022 & $1.86-17.86$ \\
\hline Neutrophil (x 109/I) ${ }^{\mathrm{a}}$ & $6.47 \pm 1.61$ & $4.36 \pm 1.78$ & 0.018 & $1.29-13.96$ \\
\hline $\begin{array}{l}\text { Lymphocyte } \\
\left.\left(\times 10^{9} / I\right)^{\mathrm{a}}\right)\end{array}$ & $2.37 \pm 0.84$ & $1.76 \pm 0.64$ & 0.107 & $0.30-3.00$ \\
\hline Monocyte & $1.17 \pm 0.46$ & $1.25 \pm 0.66$ & 0.802 & $0.01-2.50$ \\
\hline Basophil & 0 & 0 & ND & $0.00-0.08$ \\
\hline Eosinophil & $0.082 \pm 0.07$ & $0.12 \pm 0.13$ & 0.512 & $0.00-0.97$ \\
\hline Platelet & $220 \pm 69.08$ & $231.75 \pm 72.49$ & 0.755 & $63.00-177.00$ \\
\hline
\end{tabular}


of Babesia trophozoites in blood smears. We hypothesize that Babesia spp. associated with the Sunda pangolin are not pathogenic to this animal, that is, the Sunda pangolin does not develop the disease caused by Babesia spp., but it can be infected and thus play a role as a reservoir to spread Babesia spp. to other wildlife. Therefore, the pangolins we observed are asymptomatic. The previous studies have observed Amblyomma javanense, a tick from the family Ixodidae, feeding on pangolins and other hosts such as water monitor lizards (Varanus salvator) and wild boar (Sus scrofa L.) [23$26]$ and thus can be a vector for circulating Babesia spp. in the pangolin population and other hosts. However, to date, Babesia spp. we described have not been reported in other hosts. Although Babesia spp. we described here may be potentially pathogenic to Sunda pangolins, we observed only low levels of parasitemia in infected pangolins and hematological properties did not change in response to host susceptibility factors such as age and immune status. However, all the pangolins in this study were adults, that is, no juveniles were included. The severity of illness often depends on several factors such as the specific Babesia species involved or the immunocompetence of the host. For example, the severity of $B$. microti infections can range from asymptomatic to fatal, and in immunocompromised persons or those that have had a splenectomy, the severity of $B$. microti infection is higher than that in healthy persons [27]. Thus, it is possible for Babesiaaffected pangolins to develop clinical signs if their immune systems have been compromised.

Pangolin-associated Babesia spp. should be considered as a potential zoonotic pathogen. In general, forest encroachment, illegal trade of wildlife, and raising wild animals as pets increase the chances of humans and wildlife colocalization, thus increasing the risk of emerging zoonoses. The zoonotic potential of pangolin-associated Babesia spp. requires further study, particularly on the parasite's pathogenicity and transmission cycle.

\section{Conclusion}

We have detected a novel species of Babesia in Sunda pangolins. However, we did not observe any health impacts on Babesia spp. -infected pangolins, an observation that requires further study.

\section{Authors' Contributions}

RY and MS: Conceived the experimental design. RY and BS: Collected samples. RY, MS, BS, RP, and WP: Performed the experiment, data observation, and acquisition. RY, MS, NK, RP, and WP: Analyzed and interpreted the data. RY, MS, and WP: Wrote the manuscript. All authors reviewed the manuscript, read and approved the final manuscript.

\section{Acknowledgments}

The authors are thankful to the Department of National Parks Wildlife and Plant Conservation,
Bangkok, Thailand, for providing samples. This study was supported by Start Up Research Fund from Faculty of Veterinary Medicine, Kasetsart University, Thailand (grant number VET.KU2018-SRF01).

\section{Competing Interests}

The authors declare that they have no competing interests.

\section{Publisher's Note}

Veterinary World remains neutral with regard to jurisdictional claims in published institutional affiliation.

\section{References}

1. Zhang, F., Yu, J., Wu, S., Li, S., Zou, C. and Wang, Q. (2017) Keeping and breeding the rescued Sunda pangolins (Manis javanica) in captivity. Zoo Biol., 36(6): 387-96.

2. Gaubert, P., Antunes, A., Meng, H., Miao, L., Peigné, S. and Justy, F. (2018) The complete phylogeny of pangolins: Scaling up resources for the molecular tracing of the most trafficked mammals on Earth. J Hered., 109(4): 347-59.

3. Hua, L., Gong, S., Wang, F., Li, W., Ge, Y. and Li, X. (2015) Captive breeding of pangolins: Current status, problems and future prospects. Zookeys, 507(6970): 99-114.

4. Yabsley, M.J. and Shock, B.C. (2013) Natural history of zoonotic Babesia: Role of wildlife reservoirs. Int. J. Parasitol. Parasites Wildl., 2(1): 18-31.

5. Garrett, K.B., Hernandez, S.M., Balsamo, G., Barron, H., Beasley, J.C. and Brown, J.D. (2019) Prevalence, distribution, and diversity of cryptic piroplasm infections in raccoons from selected areas of the United States and Canada. Int. J. Parasitol. Parasites Wildl., 9: 224-233.

6. Jalovecka, M., Hajdusek, O., Sojka, D., Kopacek, P. and Malandrin, L. (2018) The complexity of Piroplasms life cycles. Front. Cell. Infect. Microbiol., 8(00248): 248.

7. Ostfeld, R.S., Levi, T., Jolles, A.E., Martin, L.B., Hosseini, P.R. and Keesing, F. (2014) Life history and demographic drivers of reservoir competence for three tick-borne zoonotic pathogens. PLoS One, 9(9): e107387.

8. Remesar, S., Díaz, P., Prieto, A., Markina, F., Díaz, C.J.M. and López, L.G. (2019) Prevalence and distribution of Babesia and Theileria species in roe deer from Spain. Int. J. Parasitol. Parasites Wildl., 9:195-201.

9. Svensson, J., Lazarevic, V., Bläckberg, J., Olsson, M. and Persson, K. (2019) Babesiosis could be more common in Sweden than previously thought. Lakartidningen, 116:FL4D.

10. Tonnetti, L., Townsend, R.L., Dodd, R.Y. and Stramer, S.L. (2019) Characteristics of transfusion-transmitted Babesia microti, American Red Cross (2010-2017). Transfusion, 59(9): 2908-2912.

11. Penzhorn, B.L. (2006) Babesiosis of wild carnivores and ungulates. Vet. Parasitol., 138(1-2): 11-21.

12. Zanet, S., Trisciuoglio, A., Bottero, E., de Mera, I.G., Gortazar, C. and Carpignano, M.G. (2014) Piroplasmosis in wildlife: Babesia and Theileria affecting free-ranging ungulates and carnivores in the Italian Alps. Parasite Vectors., 7(1): 70 .

13. Shih, C.M., Liu, L.P., Chung, W.C., Ong, S.J. and Wang, C.C. (1997) Human babesiosis in Taiwan: Asymptomatic infection with a Babesia microti-like organism in a Taiwanese woman. J. Clin. Microbiol., 35(2): 450-454.

14. Welc-Falęciak, R., Pawełczyk, A., Radkowski, M., Pancewicz, S.A., Zajkowska, J. and Siński, E. (2015) First report of two asymptomatic cases of human infection with Babesia microti (Franca, 1910) in Poland. Ann. Agric. Environ. Med., 22(1): 51-54.

15. Beck, R., Vojta, L., Mrljak, V., Marinculić, A., Beck, A. and 
Zivicnjak, T. (2009) Diversity of Babesia and Theileria species in symptomatic and asymptomatic dogs in Croatia. Int. J. Parasitol., 39(7): 843-848.

16. Haapasalo, K., Suomalainen, P., Sukura, A., Siikamaki, H. and Jokiranta, T.S. (2010) Fatal babesiosis in man, Finland, 2004. Emerg. Infect. Dis., 16(7): 1116-1118.

17. Vannier, E., Gewurz, B.E. and Krause, P.J. (2008) Human babesiosis. Infect. Dis. Clin. North Am., 22(3): 469-488, viii-ix.

18. Khatri-Chhetri, R., Wang, H.C., Chen, C.C., Shih, H.C., Liao, H.C. and Sun, C.M. (2016) Surveillance of ticks and associated pathogens in free-ranging Formosan pangolins (Manis pentadactyla pentadactyla). Ticks Tick Borne Dis., 7(6): 1238-1244.

19. Koh, F.X., Kho, K.L., Panchadcharam, C., Sitam, F.T. and Tay, S.T. (2016) Molecular detection of Anaplasma spp. in pangolins (Manis javanica) and wild boars (Sus scrofa) in Peninsular Malaysia. Vet. Parasitol., 227:73-76.

20. Sukmak, M., Wajjwalku, W., Lorsunyaluk, B., Kaolim, N. and Buddhakosai, W. (2015) Molecular Detection of Piroplasmida's Multiple Infection in Burmese Ferret Badger (Melogale personata). Proceedings of $53^{\text {rd }}$ Kasetsart University Annual Conference, Bangkok. p1595.

21. Tamura, K., Stecher, G., Peterson D., Filipski, A. and Kumar, S. (2013) MEGA6: Molecular evolutionary genetics analysis version 6.0. Mol. Biol. Evol., 30(12): 2725-2729.
22. Ahmad, A.A., Samsuddin, S., Oh, S.J.W., Martinez-Perez, P. and Rasedee, A. (2018) Hematological and serum biochemical parameters of rescued Sunda pangolins (Manis javanica) in Singapore. J. Vet. Med Sci., 80(20): 1867-1874.

23. Hassan, M., Sulaiman, M.H. and Lian, C.J. (2013) The prevalence and intensity of Amblyomma javanense infestation on Malayan pangolins (Manis javanica Desmarest) from Peninsular Malaysia. Acta Trop., 126(2): 142-145.

24. Jabin, G., Dewan, Y., Khatri, H., Singh, S.K., Chandra, K. and Thakur, M. (2019) Identifying the tick Amblyomma javanense (Acari: Ixodidae) from Chinese pangolin: Generating species barcode, phylogenetic status and its implication in wildlife forensics. Exp. Appl. Acarol., 78(3): 461-467.

25. Kollars, T.M. and Sithiprasasna, R. (2000) New host and distribution record of Amblyomma javanense (Acari: Ixodidae) in Thailand. J. Med. Entomol., 37(4): 640.

26. Kwak, M.L., Hsu, C.D., Douay, G. and Ahmad, A.A. (2018) Correction to: The first authenticated record of the pangolin tick Amblyomma javanense (Acari: Ixodidae) in Singapore, with notes on its biology and conservation. Exp. Appl. Acarol., 76(4): 559.

27. Rosner, F., Zarrabi, M.H., Benach, J.L. and Habicht, G.S. (1984) Babesiosis in splenectomized adults. Review of 22 reported cases. Am. J. Med., 76(4): 696-701.

$* * * * * * * *$ 